\title{
Severe asthma exists despite suppressed tissue inflammation: findings of the U-BIOPRED study
}

\author{
Susan J. Wilson ${ }^{1}$, Jonathan A. Ward ${ }^{1}$, Ana R. Sousa ${ }^{2}$, Julie Corfield ${ }^{3,4}$, \\ Aruna T. Bansal ${ }^{5}$, Bertrand De Meulder ${ }^{6}$, Diane Lefaudeux 6 , Charles Auffray ${ }^{6}$, \\ Matthew J. Loza ${ }^{7}$, Frederic Baribaud ${ }^{7}$, Neil Fitch ${ }^{8}$, Peter J. Sterk ${ }^{9}$, \\ Kian Fan Chung ${ }^{10}$, David Gibeon ${ }^{10}$, Kai Sun ${ }^{10}$, Yi-ke Guo ${ }^{10}$, Ian Adcock ${ }^{10}$, \\ Ratko Djukanovic ${ }^{1}$, Barbro Dahlen ${ }^{11}$, Pascal Chanez ${ }^{12}$, Dominick Shaw ${ }^{13}$, \\ Norbert Krug ${ }^{14}$, Jens Hohlfeld ${ }^{14}$, Thomas Sandström ${ }^{15}$ and Peter H. Howarth ${ }^{1}$ \\ on behalf of the U-BIOPRED Study Group ${ }^{16}$
}

ABSTRACT The U-BIOPRED study is a multicentre European study aimed at a better understanding of severe asthma. It included three steroid-treated adult asthma groups (severe nonsmokers (SAn group), severe current/ex-smokers (SAs/ex group) and those with mild-moderate disease (MMA group)) and healthy controls (HC group). The aim of this cross-sectional, bronchoscopy substudy was to compare bronchial immunopathology between these groups.

In 158 participants, bronchial biopsies and bronchial epithelial brushings were collected for immunopathologic and transcriptomic analysis. Immunohistochemical analysis of glycol methacrylate resin-embedded biopsies showed there were more mast cells in submucosa of the HC group $\left(33.6 \mathrm{~mm}^{-2}\right)$ compared with both severe asthma groups (SAn: $17.4 \mathrm{~mm}^{-2}, \mathrm{p}<0.001$; SAs/ex: $22.2 \mathrm{~mm}^{-2}, \mathrm{p}=0.01$ ) and with the MMA group $\left(21.2 \mathrm{~mm}^{-2}, \mathrm{p}=0.01\right)$. The number of $\mathrm{CD} 4^{+}$lymphocytes was decreased in the SAs/ex group $\left(4.7 \mathrm{~mm}^{-2}\right)$ compared with the SAn $\left(11.6 \mathrm{~mm}^{-2}, \mathrm{p}=0.002\right)$, MMA $\left(10.1 \mathrm{~mm}^{-2}, \mathrm{p}=0.008\right)$ and $\mathrm{HC}\left(10.6 \mathrm{~mm}^{-2}, \mathrm{p}<0.001\right)$ groups. No other differences were observed.

Affymetrix microarray analysis identified seven probe sets in the bronchial brushing samples that had a positive relationship with submucosal eosinophils. These mapped to COX-2 (cyclo-oxygenase-2), ADAM-7 (disintegrin and metalloproteinase domain-containing protein 7), SLCO1A2 (solute carrier organic anion transporter family member 1A2), TMEFF2 (transmembrane protein with epidermal growth factor like and two follistatin like domains 2) and TRPM-1 (transient receptor potential cation channel subfamily $\mathrm{M}$ member 1); the remaining two are unnamed.

We conclude that in nonsmoking and smoking patients on currently recommended therapy, severe asthma exists despite suppressed tissue inflammation within the proximal airway wall.

$@$ ERSpublications

Severe asthma exists despite suppressed tissue inflammation in proximal airways when on current recommended therapy http://ow.ly/1rb6303haKP

This article has supplementary material available from erj.ersjournals.com

Received: June 072016 | Accepted after revision: Aug 102016 | First published online: Oct 062016

Support statement: The U-BIOPRED study would have not been possible without the Innovative Medicines Initiative (IMI) funding provided by the European Union and the European Federation of Pharmaceutical Industries and Associations (EFPIA). Funding information for this article has been deposited with the Open Funder Registry.

Conflict of interest: Disclosures can be found alongside this article at erj.ersjournals.com

Copyright OERS 2016 
Affiliations: ${ }^{1}$ Faculty of Medicine, University of Southampton and NIHR Respiratory Biomedical Research Unit, University of Southampton NHS Foundation Trust, Southampton, UK. ${ }^{2}$ GlaxoSmithKline, Stevenage, UK. ${ }^{3}$ AstraZeneca, Mölndal, Sweden. ${ }^{4}$ Areteva, Nottingham, UK. ${ }^{5}$ Acclarogen, Cambridge, UK. ${ }^{6}$ European Institute for Systems Biology and Medicine, CIRI UMR5308, CNRS-ENS-UCBL-INSERM, Lyon, France. ${ }^{7}$ Janssen R\&D, Spring House, PA, USA. ${ }^{8}$ BioSciConsulting, Maasmechelen, Belgium. ${ }^{9}$ Academic Medical Centre, University of Amsterdam, Amsterdam, The Netherlands. ${ }^{10}$ Imperial College London, London, UK. ${ }^{11}$ Centre for Allergy Research, Karolinska Institute, Stockholm, Sweden. ${ }^{12}$ Université de la Médierranee, Marseille, France. ${ }^{13}$ Centre for Respiratory Research, University of Nottingham, Nottingham, UK. ${ }^{14}$ Fraunhofer Institute of Toxicology and Experimental Medicine, Hannover, Germany. ${ }^{15}$ Dept of Respiratory Medicine, Umeå University, Umeå, Sweden. ${ }^{16}$ The members of the U-BIOPRED Study Group are listed in the Acknowledgement section.

Correspondence: Susan J. Wilson, Histochemistry Research Unit, Sir Henry Wellcome Laboratories, Mailpoint 894, Level B, South Block, Southampton General Hospital, Tremona Road, Southampton S016 6YD, UK. E-mail: S.J.Wilsondsouthampton.ac.uk

\section{Introduction}

Asthma is a heterogeneous disorder that varies in severity and response to treatment. Many different cell populations are involved, including structural airway cells as well as infiltrating leukocytes [1]. To date, however, there are no pathological markers that distinguish severe asthma from less severe disease, although some inflammatory and remodelling features are reported to have greater expression. These include increased neutrophil numbers in sputum [2], biopsies and bronchoalveolar lavage fluid [3, 4], an increase in the area of airway smooth muscle and glands [4-6], as well as increased thickness of the lamina reticularis [4, 7]. However, these observations are not unanimous, with some publications identifying no increase in neutrophils [5] or in the thickness of the lamina reticularis [5, 6] in severe asthma compared with mild or moderate asthma. These discrepancies may reflect the range of clinical and pathological phenotypes described in asthma [7-12], and the inclusion of these differing populations.

Severe asthma has been divided into eosinophilic and noneosinophilic phenotypes when airway inflammation is assessed in sputum or endobronchial biopsies [4, 8, 9, 13-16]. In severe asthma with bronchial mucosal eosinophilia, there are also increased numbers of airway lymphocytes, mast cells and macrophages, together with increased thickness of the lamina reticularis $[13,16]$. These findings differ from those in severe asthma without eosinophils but not in mild asthma or healthy individuals [13]. Those with eosinophilic disease are the most responsive to steroid therapy [16, 17], although in severe asthma airway eosinophilia can persist despite such treatment. Not all severe asthma is, however, eosinophilic [4, 13-15].

Whilst previously there have been several large multicentre studies of severe asthma, including the two European studies ENFUMOSA (European network for understanding mechanisms of severe asthma) and BIOAIR (Longitudinal Assessment of Clinical Course and Biomarkers in Severe Chronic Airway Disease), and the SARP (Severe Asthma Research Program) study in the USA [18], there is still a need to better understand the basis for disease persistence and inflammatory phenotypes in severe asthma to permit the stratified application of novel therapies. Towards this end, the U-BIOPRED (Unbiased Biomarkers for the Predictions of Respiratory Disease Outcomes) consortium aimed to subphenotype severe asthma using an innovative systems medicine approach. This comprehensive study included a variety of "omics" technologies applied to bronchoscopic airway, sputum and blood samples, noninvasive sampling with exhaled breath measures, together with clinical and pathological characterisation conducted using the same standard operating procedures (SOPs) across all centres. The aim of the study reported here was to investigate the immunopathology in the airways of severe asthma subjects as compared with mildmoderate asthma subjects and healthy controls. In addition, we examined the association of smoking with airway pathology in severe asthma. We also looked at the influence of stratification by eosinophilia and neutrophilia, and the relationship of this to gene expression.

\section{Methods}

Study design

The U-BIOPRED study is a multicentre study involving 20 academic centres in 11 European countries, 11 pharma partners and six patient organisations. Three steroid-treated adult asthma groups (severe nonsmokers (SAn group), severe current/ex-smokers (SAs/ex group) and those with mild-moderate disease (MMA group)), classified and treated according to the Global Initiative for Asthma guidelines, as well as healthy controls (HC group) were recruited in the main U-BIOPRED study. Definitions for each group were agreed at a consensus meeting prior to study start, and are described in full by SHAW et al. [19] and in the online supplementary material. At baseline, participants underwent clinical screening to assess demographics, comorbidities, asthma symptoms, asthma history, treatment and lung function. Induced sputum and blood samples were collected for assessment of inflammatory cell profile and "omics" analysis with measures of the exhaled nitric oxide fraction $\left(F_{\mathrm{eNO}}\right)$. 
Eight of the clinical centres took part in a cross-sectional bronchoscopy substudy. An ethics review committee approved the study in each of these centres and all study volunteers gave written informed consent.

\section{Bronchoscopy procedure and collection of samples}

Participants undergoing bronchoscopy had to meet the inclusion criteria for the main study [19] and none of the bronchoscopy exclusion criteria (see online supplementary material). All the participating centres followed SOPs for the bronchoscopy, airway sampling and processing (see online supplementary material).

Up to eight proximal airway endobronchial biopsies were collected from each subject: three for immunohistochemistry (processed into glycol methacrylate resin (GMA)), three for transcriptomics (placed into RNAlater stabilising reagent), and up to two biopsies fixed in $10 \%$ neutral buffered formalin and embedded in paraffin wax for biobanking for future use. Biopsies were initially processed at the clinical centres according to the SOPs, with each centre having received training and undergone a pre-study biopsy quality control assessment, before shipping to a central laboratory for analysis or to the centralised biobank for storage in accordance with international guidelines. Epithelial brushings were collected from the proximal airways using disposable, sheathed bronchial brushes and placed in PBS for processing for transcriptomics.

\section{Bronchial biopsy immunohistochemical analysis}

Immunohistochemical analysis of the GMA resin-embedded biopsies was undertaken, as previously described [20], in the Histochemistry Research Unit at the University of Southampton (Southampton, UK). Only biopsies passing defined quality criteria (see online supplementary material) were immunohistochemically stained for the presence of mast cells, eosinophils, neutrophils and macrophages, as well as $\mathrm{CD}^{+}, \mathrm{CD}^{+}, \mathrm{CD}^{+}$and $\mathrm{CD} 25^{+}$lymphocytes. Sections were also stained to identify airway smooth muscle (ASM).

Positive nucleated cells were enumerated as cells per square millimetre of submucosa and ASM, and per millimetre length of epithelium. This was derived by counting cells in the submucosa, ASM and epithelium in each section, calculating the mean number for each cell type for each subject, and measuring the area of the submucosa and ASM; epithelial length was determined using a calibrated image analysis system. The thickness of the lamina reticularis was also assessed with the assistance of computerised image analysis [21]. A point counting grid was used on the sections stained for $\alpha$-smooth muscle actin to determine the muscle proportion, i.e. the volume fraction (proportion) [22]. SOPs for these methods are in the online supplementary material.

\section{Transcriptomic analysis of biopsies and brushings}

The RNAlater samples were shipped to a single site via the biobank for assessment of RNA quality, transcriptomic processing and analysis. RNA was isolated from the samples using a miRNeasy kit (Qiagen, Germantown, MD, USA) and amplified with a Ovation Pico WTA kit (NuGen Technologies, San Carlos, CA, USA). The cDNA was analysed using a HT HG-U133+ PM microarray platform (Affymetrix, Santa Clara, CA, USA). Quality checks were performed following Affymetrix's recommendations and post-analysis (see online supplementary material for further details).

\section{Data analysis}

Initial analysis of immunohistochemical, sputum, blood, exhaled air and clinical data was by ANOVA to test for differences between groups, and then where relevant either nonparametric or parametric analysis was applied to evaluate the significance of group differences using SPSS version 19 (IBM, Armonk, NY, USA). Spearman's rank test was applied to test for pairwise correlation.

The background-corrected, normalised transcriptomic data for the bronchial biopsies and bronchial brushings were tested for association with submucosal eosinophil and neutrophil counts using a general linear model, adjusting for covariates age and gender, and correction for false discovery rate (see online supplementary material for further details). Analyses were conducted using R version 3.2.2 (www.r-project.org).

\section{Stratification by eosinophil and neutrophil number}

To investigate the relevance of eosinophilia and neutrophilia to immunohistochemical, blood and sputum cell count data, and FeNO, as well as clinical characteristics, data were divided into low and high groups based on the mean+2SD eosinophil and neutrophil submucosal count in the HC group [12].

\section{Results}

A total of 160 participants underwent bronchoscopy, two of which were withdrawn from the study due to protocol violations. Of the remaining 158, biopsies suitable for immunohistochemistry were obtained from $87 \%$ of the participants $(n=137)$ with a mean of 1.4 suitable biopsies per participant. These comprised 46 
in the SAn group, 16 in the SAs/ex group, 34 in the MMA group and 41 in the HC group. The baseline clinical data and inflammatory cell profiles in the induced sputum and blood are summarised in table 1, and the biopsy data are summarised in table 2. The four groups for ANOVA ranged in size from 16 to 46. Under the simplifying assumption of equal group sizes $(n=39)$, there is $15 \%, 74 \%$ and $>95 \%$ power to detect small, medium and large effect sizes, respectively, at the 5\% level. The three effect sizes were parameterised by Cohen's f, taking accepted values of $0.1,0.25$ and 0.4 , respectively [23]. It is acknowledged that some small or moderate effects are likely to have been missed.

\section{Participant demographics}

The bronchoscopy subgroup demographics were similar to the overall study [19]. The participants in both severe asthma (SAn and SAs/ex) groups were older, had a higher body mass index, lower forced expiratory volume in $1 \mathrm{~s}(\mathrm{FEV} 1)$, more exacerbations and increased prevalence of nasal polyps than the MMA and $\mathrm{HC}$ groups. Atopy and rhinitis were increased compared with the HC group but not the MMA group. There was more gastro-oesophageal reflux disease in the SAn group compared with the MMA group and rhinitis was more prevalent in the SAn group compared with the SAs/ex group.

\section{TABLE 1 Subject characteristics: bronchoscopy cohort}

\begin{tabular}{|c|c|c|c|c|}
\hline & \multicolumn{4}{|c|}{ Group } \\
\hline Subjects & 46 & 16 & 34 & 41 \\
\hline \multicolumn{5}{|l|}{ Sex } \\
\hline Female & 24 & 7 & 19 & 13 \\
\hline Male & 22 & 9 & 15 & 28 \\
\hline Exacerbations in last year ${ }^{\uparrow, \S}$ & $2.8 \pm 0.3(n=34)$ & $2.9 \pm 0.4(n=12)$ & $1.4 \pm 0.4(n=34)$ & NA \\
\hline \multicolumn{5}{|l|}{ Smoking history } \\
\hline Never-smoker & 83 & & 88 & 80 \\
\hline Current smoker & & 31 & & \\
\hline Ex-smoker (<5 pack-years) & 17 & 69 & 12 & 20 \\
\hline Positive atopic status $s^{\eta,+, f, \# \#}$ & $33 / 43(77)$ & $12 / 14(86)$ & $278 / 28(96)$ & $14 / 30(47)$ \\
\hline Anti-lgE & $5 / 41(12)$ & $1 / 12(8)$ & NA & NA \\
\hline Antibiotics & $12 / 43(28)$ & $5 / 11(45)$ & NA & NA \\
\hline LT modifier & 26/44 (59) & $7 / 14(50)$ & NA & NA \\
\hline Macrolides & $8 / 46(17)$ & $7 / 15(47)$ & NA & NA \\
\hline OCS & $19 / 44(43)$ & $7 / 14(50)$ & NA & NA \\
\hline Xanthines & 7/42 (17) & $1 / 12(8)$ & NA & NA \\
\hline$F_{\mathrm{eNO}} \mathrm{ppb}^{\#,+}$ & $38.0(20.0-60.5)(n=41)$ & $20.0(12.5-34.3)(n=15)$ & $22.0(17.5-55.0)(n=34)$ & $18.3(14.5-29.0)(n=38)$ \\
\hline \multicolumn{5}{|l|}{ Blood eosinophils } \\
\hline Count $\times 10^{3} \mu \mathrm{L}^{-1+, \# \#}$ & $0.3(0.1-0.4)$ & $0.2(0.2-0.2)$ & $0.2(0.1-0.3)$ & $0.1(0.1-0.2)$ \\
\hline$\%$ & $3.6(1.7-6.3)$ & $1.8(1.2-3.6)$ & $3.1(1.9-5.55)$ & $2.3(1.5-3.3)$ \\
\hline \multicolumn{5}{|l|}{ Blood neutrophils } \\
\hline Count $\times 10^{3} \mu \mathrm{L}^{-1 \#, q,+, \S, f}$ & $4.8(3.4-6.1)$ & $6.84(4.0-8.6)$ & $3.2(2.7-4.6)$ & $2.7(2.2-3.7)$ \\
\hline
\end{tabular}

Data are presented as $\mathrm{n}$, mean $\pm \mathrm{SE}, \%, \mathrm{n} / \mathrm{N}(\%)$ or median (interquartile range), unless otherwise stated. If there is missing data the number of subjects data is available from is given. SAn: severe asthma nonsmokers; SAs/ex: severe asthma current/ex-smokers; MMA: mild-moderate asthma; HC: healthy controls; BMI: body mass index; FEV1: forced expiratory volume in $1 \mathrm{~s}$; GORD: gastro-oesophageal reflux disease; LT: leukotriene; OCS: oral corticosteroid; FeNO: exhaled nitric oxide fraction. Differences ( $p<0.05)$ are indicated as: ${ }^{\#}$ : SAn versus SAs/ex; ${ }^{\text {": }}$ SAn versus MMA; ${ }^{+}$: SAn versus HC; ${ }^{\S}$ : SAs/ex versus MMA; ${ }^{f}$ : SAs/ex versus HC; ${ }^{\# \#}$ : MMA versus HC. 
TABLE 2 Summary of biopsy immunopathology results

\begin{tabular}{|c|c|c|c|c|}
\hline & \multicolumn{4}{|c|}{ Group } \\
\hline Subjects & 46 & 16 & 34 & 41 \\
\hline Submucosa & 46 & 16 & 34 & 41 \\
\hline ASM & 39 & 13 & 31 & 37 \\
\hline Epithelium & 37 & 16 & 31 & 28 \\
\hline \multicolumn{5}{|l|}{ Mast cells } \\
\hline Submucosa $\mathrm{mm}^{-2 \uparrow, \S, f}$ & $17.4(8.7-27.1)$ & $22.2(1.1-35.8)$ & $21.2(16.3-34.1)$ & $33.6(25.9-43.3)$ \\
\hline ASM mm $m^{-2}$ & $5.3(0-13.8)$ & $10.3(0.8-16.7)$ & $9.6(3.7-26.4)$ & $14.3(2.6-22.3)$ \\
\hline Epithelium $\mathrm{mm}^{-1}$ & $0(0-1.9)$ & $0(0-0.4)$ & $0(0-2.3)$ & $0(0-1.6)$ \\
\hline \multicolumn{5}{|l|}{ Eosinophils } \\
\hline Submucosa $\mathrm{mm}^{-2}$ & $3.4(1.1-7.6)$ & $2.1(0.8-5.0)$ & $2.1(0.6-5.6)$ & $2.1(0.6-4.9)$ \\
\hline \multicolumn{5}{|l|}{ Macrophages } \\
\hline Submucosa mm $\mathrm{m}^{-2}$ & $2.2(1.1-5.3)$ & $2.1(0.7-3.8)$ & $3.0(0.9-4.4)$ & $2.2(1.1-4.26)$ \\
\hline \multicolumn{5}{|l|}{ CD3 $^{+}$lymphocytes } \\
\hline Submucosa $\mathrm{mm}^{-2}$ & $35.8(22.4-45.3)$ & $20.6(13.0-35.5)$ & $35.9(22.2-50.9)$ & $36.8(24.7-70.2)$ \\
\hline Epithelium mm ${ }^{-1}$ & $1.5(0-5.9)$ & $2.2(1.1-7.8)$ & $1.7(0-7.3)$ & $2.9(1.4-7.8)$ \\
\hline \multicolumn{5}{|l|}{$\mathrm{CD4}^{+}$lymphocytes } \\
\hline Submucosa $\mathrm{mm}^{-2 \#,+, \S}$ & $11.6(5.1-18.8)$ & $4.7(2.9-6.9)$ & $10.1(4.0-19.1)$ & $10.6(7.6-22.3)$ \\
\hline \multicolumn{5}{|l|}{$\mathrm{CD8}^{+}$lymphocytes } \\
\hline Submucosa $\mathrm{mm}^{-2}$ & $15.9(5.3-30.0)$ & $12.7(5.2-21.4)$ & $14.6(7.1-26.4)$ & $21.0(11.8-37.8)$ \\
\hline Epithelium mm $\mathrm{m}^{-1}$ & $0.3(0-2.6)$ & $1.3(0.9-4.8)$ & $0.45(0-3.8)$ & $1.95(0.6-4.5)$ \\
\hline Lamina reticularis thickness $\mu \mathrm{m}$ & $8.9(7.3-10.2)$ & $8.7(7.9-9.9)$ & $9.0(7.7-9.7)$ & $8.8(8.0-9.2)$ \\
\hline ASM volume fraction & $0.3(0.2-0.4)$ & $0.3(0.2-0.4)$ & $0.3(0.3-0.5)$ & $0.3(0.2-0.4)$ \\
\hline
\end{tabular}

Data are presented as $\mathrm{n}$ or median (interquartile range). Zero data is not shown. SAn: severe asthma nonsmokers; SAs/ex: severe asthma current/ex-smokers; MMA: mild-moderate asthma; HC: healthy controls; ASM: airway smooth muscle. Differences ( $p<0.05)$ are indicated as: ${ }^{\#}$ : SAn versus SAs/ex; ${ }^{\text {ๆ }}$ : SAn versus $\mathrm{HC}^{+}{ }^{+}$: SAs/ex versus MMA; ${ }^{8}$ : SAs/ex versus $\mathrm{HC}^{f}{ }^{f}$ : MMA versus HC.

\section{Baseline inflammatory measures}

A number of differences were detected between the four groups. The percentage of sputum eosinophils was higher in the SAn group than in the MMA group, and in both the SAn and SAs/ex groups than in the HC group. The percentage of sputum neutrophils was higher in the SAn and MMA groups than in the HC group. Neutrophils in the peripheral blood were higher in the SAs/ex group compared with the SAn group, and in both severe asthma groups (SAn and SAs/ex) were higher than in the MMA and HC groups. There was no difference in peripheral blood eosinophilia between the groups. FeNO was higher in the SAn group compared with the SAs/ex and HC groups.

\section{Immunopathology data}

Differences were observed across the four groups in the number of submucosal mast cells $(\mathrm{p}=0.001)$ and submucosal $\mathrm{CD}^{+}$lymphocytes $(\mathrm{p}=0.004)$. There were no other across-group differences. There were higher numbers of mast cells in the bronchial submucosa in the HC group, with a median of $33.6 \mathrm{~mm}^{-2}$, compared with all three asthma (SAn, SAs/ex and MMA) groups (figure 1a). Mast cell median numbers were $17.6 \mathrm{~mm}^{-2}$ in the SAn $(\mathrm{p}<0.001), 22.2 \mathrm{~mm}^{-2}$ in the SAs/ex $(\mathrm{p}=0.014)$ and $21.3 \mathrm{~mm}^{-2}$ in the MMA $(\mathrm{p}=0.012)$ groups. There were significantly fewer $\mathrm{CD} 4^{+}$lymphocytes in the submucosa of the SAs/ex group $\left(4.7 \mathrm{~mm}^{-1}\right)$ compared with the SAn $\left(11.6 \mathrm{~mm}^{-2}, \mathrm{p}=0.001\right)$, MMA $\left(10.1 \mathrm{~mm}^{-2}, \mathrm{p}=0.008\right)$ and HC $\left(10.6 \mathrm{~mm}^{-2}, \mathrm{p}<0.001\right)$ groups (figure $\left.1 \mathrm{~b}\right)$.

A positive relationship, across all groups was observed between percentage blood eosinophils and submucosal eosinophils ( $r h o=0.462, \mathrm{p}<0.001$ ), but there was no relationship with sputum eosinophils. In addition, both blood eosinophils and submucosal eosinophils correlated with the thickness of the lamina reticularis ( $\mathrm{rho}=0.222, \mathrm{p}=0.021$ and $\mathrm{rho}=0.21, \mathrm{p}=0.023$, respectively). Furthermore, eosinophils in blood, submucosa and sputum correlated with FeNO ( $\mathrm{rho}=0.325, \mathrm{p}<0.001, \mathrm{rho}=0.440, \mathrm{p}<0.001$ and rho=0.218, $\mathrm{p}=0.014$, respectively) (figure 2 ). FEV1 \% pred had an inverse relationship with neutrophils in the blood 

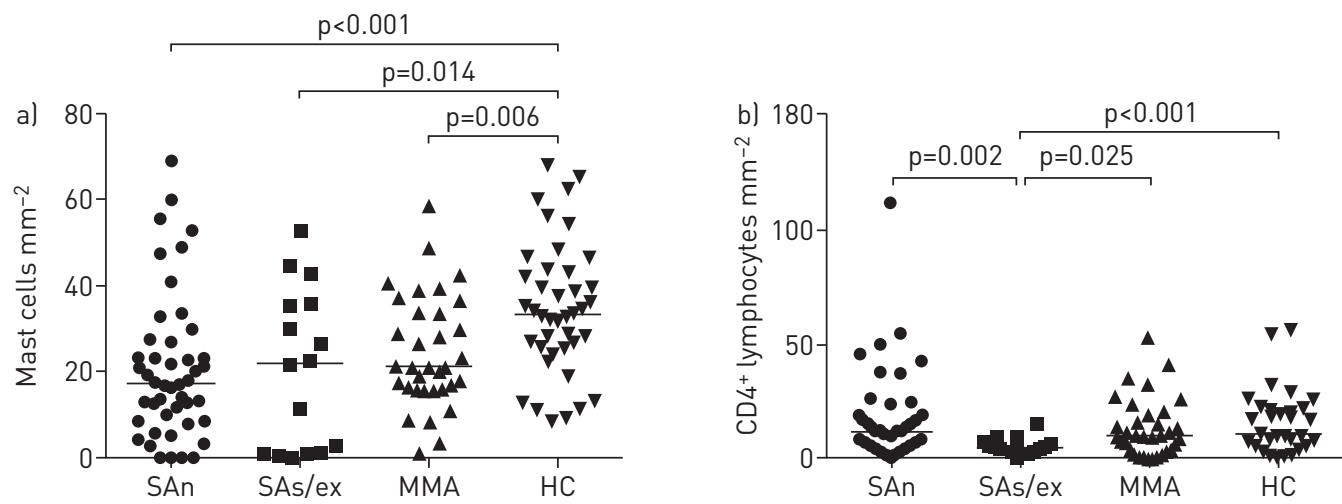

FIGURE 1 a) Mast cells and b) $\mathrm{CD}^{+}$lymphocytes in the bronchial submucosa in severe asthma nonsmokers (SAn group), severe asthma current/ex-smokers (SAs/ex group), mild-moderate asthma (MMA group) and healthy controls (HC group). Median values and significant differences between the groups are indicated.

(rho $=-0.253, \mathrm{p}=0.003$ ), eosinophils and neutrophils in sputum ( $\mathrm{rho}=-0.394, \mathrm{p}=0.001$ and $\mathrm{rho}=-0.315$, $\mathrm{p}=0.009$, respectively) and $\mathrm{FeNO}(\mathrm{rho}=-0.197, \mathrm{p}=0.026)$, and a positive relationship with mast cells in the submucosa (rho=0.356, $\mathrm{p}<0.001$ ) (figure 3).

\section{Transcriptomic data}

Seven probes were associated in the bronchial brushing samples with submucosal eosinophils after adjustment for age and gender and correction for false discovery rate (figure 4). Five probes (1553569_PM_at, 211239_PM_s_at, 207308_PM_at, 224321_PM_at and 237070_PM_at) mapped to genes: COX-2 (cyclo-oxygenase-2), ADAM-7 (disintegrin and metalloproteinase domain-containing protein 7), SLCO1A2 (solute carrier organic anion transporter family member 1A2), TMEFF2 (transmembrane protein with epidermal growth factor like and two follistatin like domains 2) and TRPM-1 (transient receptor
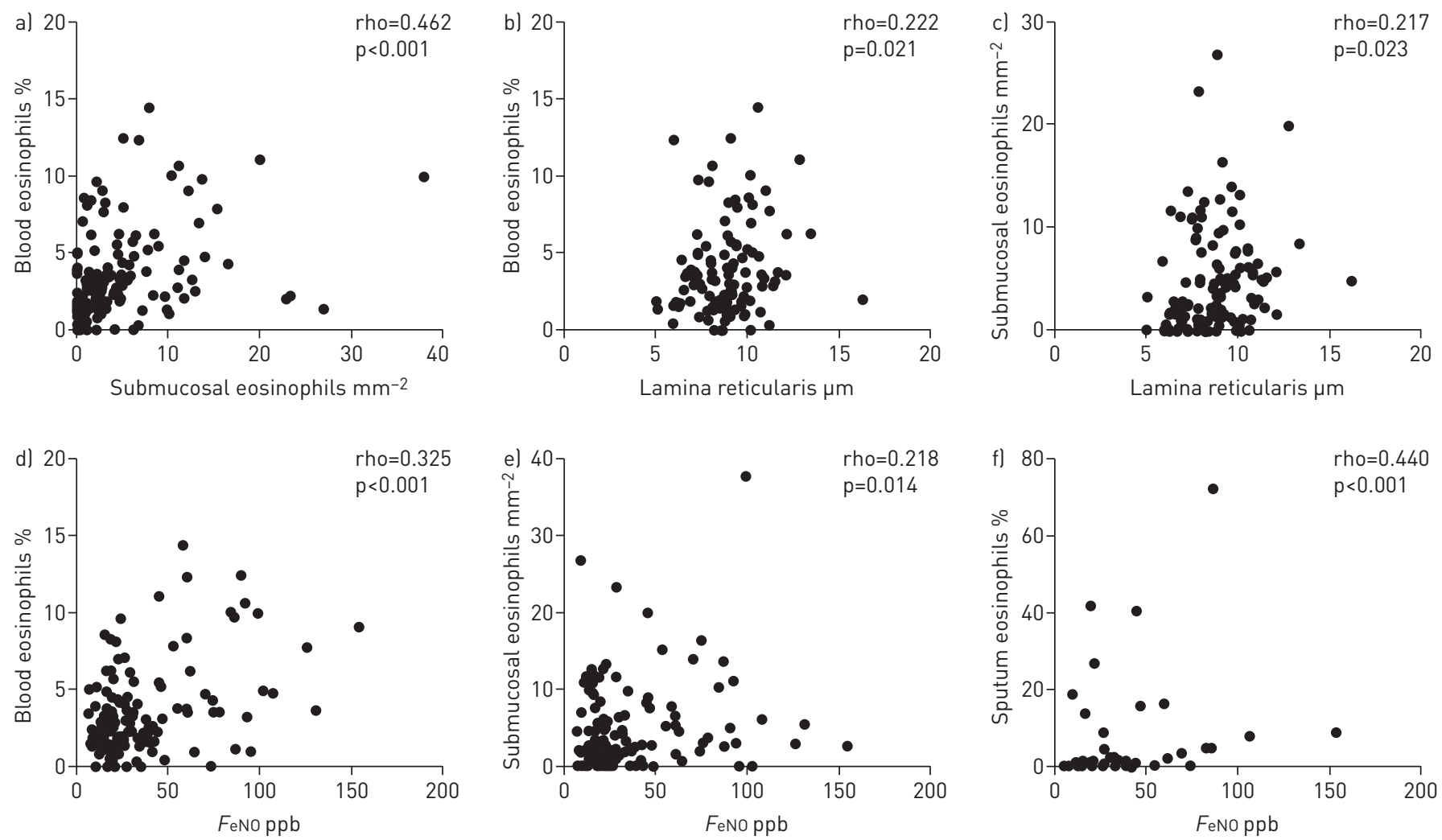

FIGURE 2 Immunopathology correlations. There was a positive relationship between a) blood eosinophils and submucosal eosinophils, and both b] blood eosinophils and c) submucosal eosinophils with the thickness of the lamina reticularis. Eosinophils in d) blood, e) submucosa and f) sputum correlated with exhaled nitric oxide fraction $\left(F_{\mathrm{e} N \mathrm{O}}\right)$. 

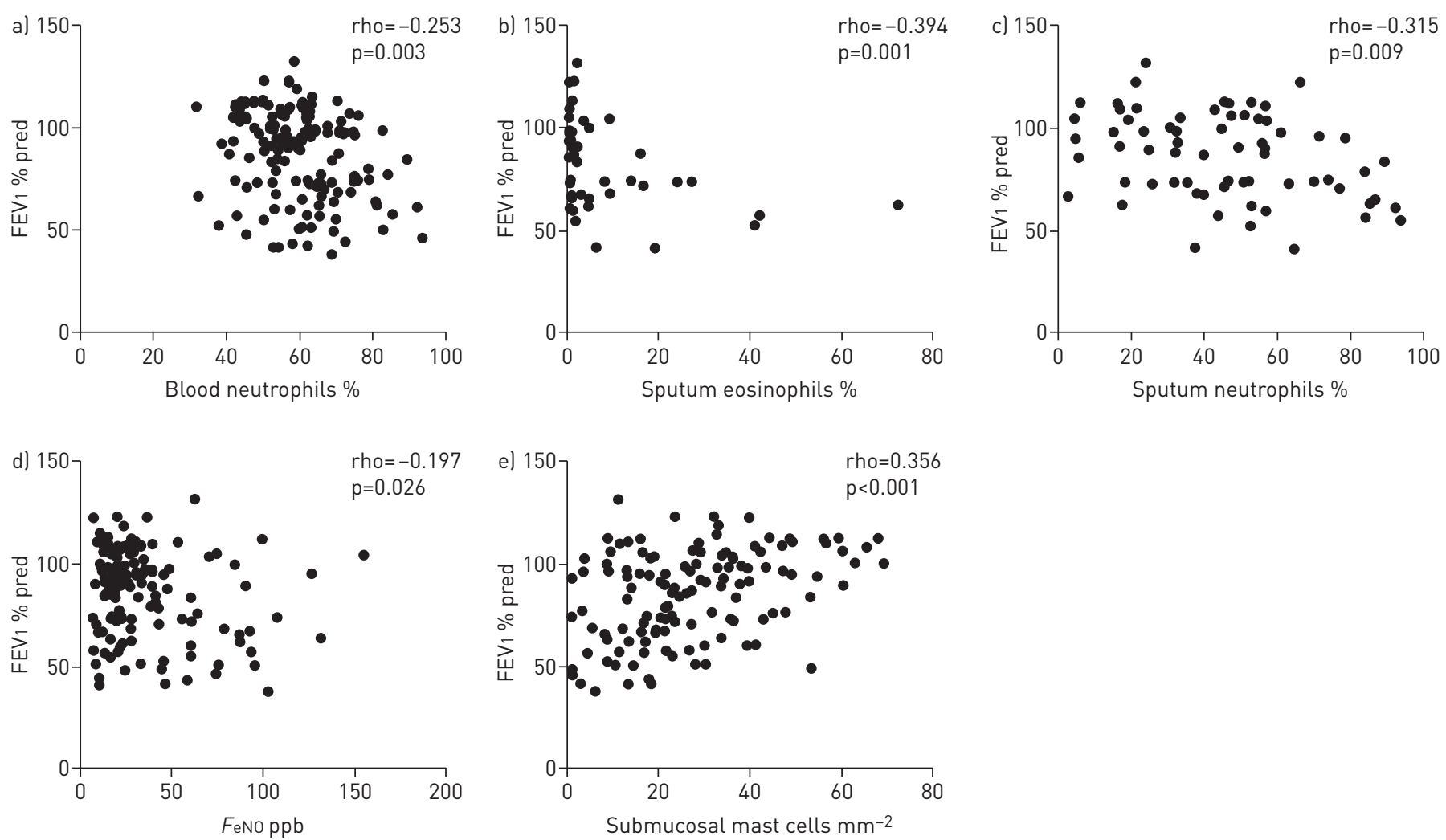

FIGURE 3 Immunopathology and clinical correlations. There was an inverse relationship between forced expiratory volume in $1 \mathrm{~s}$ (FEV 1 ) \% pred

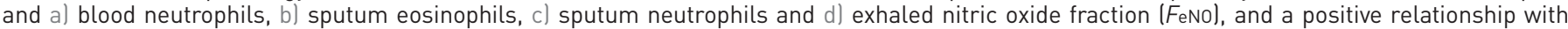
e) submucosal mast cells.

potential cation channel subfamily M member 1). The remaining two were unmapped: 224372_PM_at and 224375_PM_at. There was no significant relationship with submucosal neutrophils.

After correction there were no signification correlations between gene expression, at the individual gene level, and either submucosal eosinophils or neutrophils in the bronchial biopsies.

\section{Stratification}

The cut-off for grouping into low or high eosinophils within the submucosa, based on the U-BIOPRED HC group data $($ mean $+2 \mathrm{SD})$, was 12.63 eosinophils $\mathrm{mm}^{-2}$. This resulted in 11 participants being allocated to the eosinophil-high group; the remaining $(\mathrm{n}=126)$ were in the eosinophil-low group. There were no differences in the clinical characteristics between the eosinophil-low and -high groups. The percentage of eosinophils in the blood and sputum, and the numbers of submucosal eosinophils, macrophages, $\mathrm{CD} 3^{+}, \mathrm{CD} 4^{+}, \mathrm{CD}^{+}$and $\mathrm{CD} 25^{+}$T-lymphocytes were all significantly higher in the eosinophil-high group compared with the eosinophil-low group $(\mathrm{p}<0.05)$ (table 3 ). Only five participants with asthma had submucosal neutrophil counts outside the mean $+2 \mathrm{SD}$ range of the healthy controls. This was too few for statistical comparisons.

\section{Discussion}

The participants in this bronchoscopy study were representative, with regard to clinical characteristics, and blood and sputum cells counts, of those in the main U-BIOPRED study [19]. Here, we added bronchial immunopathology to our initial study [19], and show that in both severe and mild-moderate asthma there are less mast cells within the bronchial submucosa than in healthy individuals. Also, in severe asthma smokers there are less $\mathrm{CD}^{+}$lymphocytes in the bronchial submucosa compared with severe asthma nonsmokers. We observed relationships between the inflammatory profiles in the different airway compartments and with clinical measures of disease. Stratification by biopsy eosinophilia revealed a typical type 2 pattern of inflammation. Finally, we identified seven gene probes in the bronchial epithelial cells that were related to biopsy eosinophilia. These data indicate that those with stable severe asthma on adequate therapy do not have major changes in inflammatory cell infiltration within the bronchial mucosa of their large airways, suggesting that disease severity is mostly driven by other mechanisms, such as cellular activation status or inflammation elsewhere. There were 158 eligible participants in this 

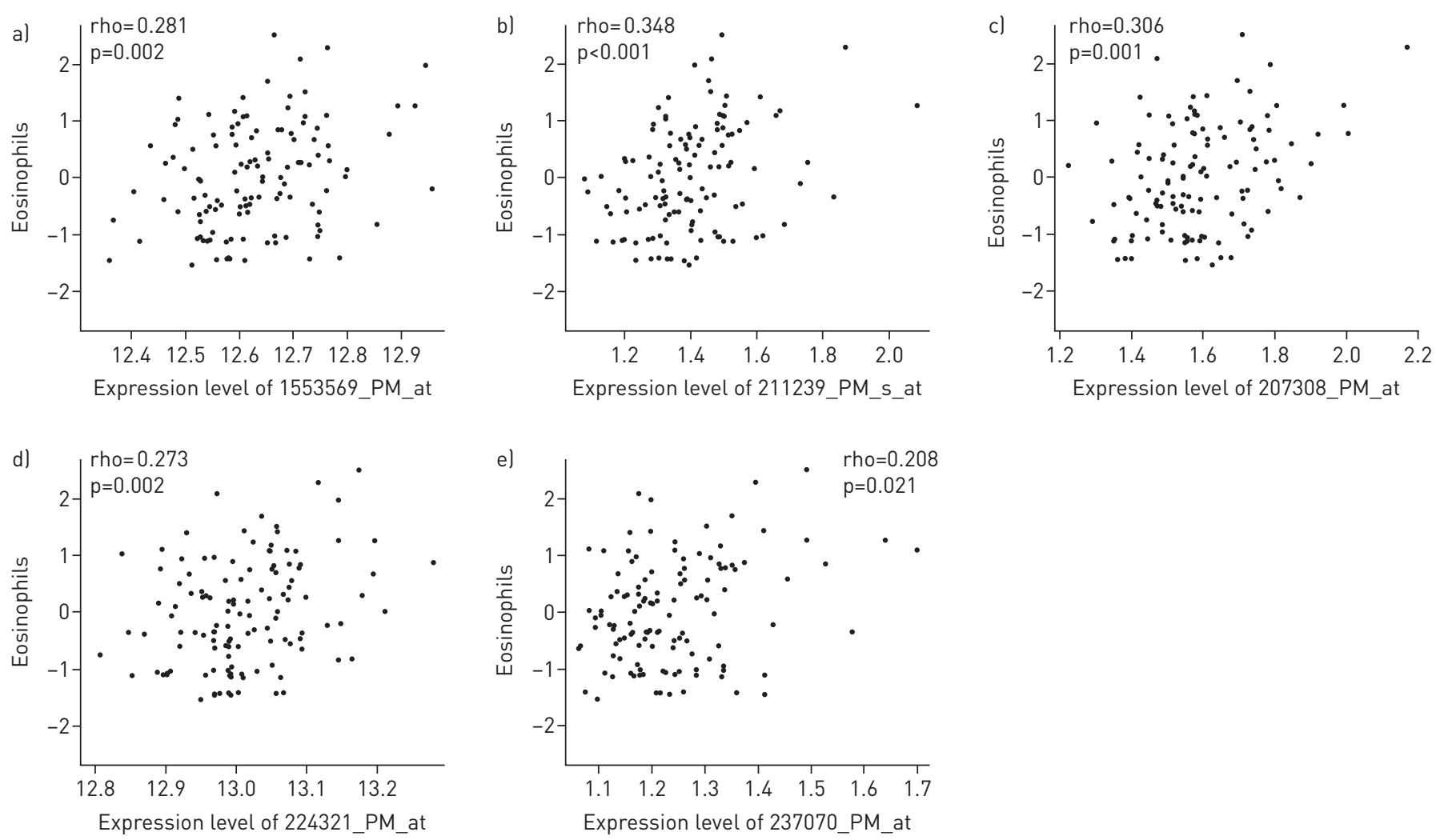

FIGURE 4 Transcriptomic data. The expression of five probes sets ( $\log _{2}$ normalised intensity) for a) COX-2 (cyclo-oxygenase-2), b) $A D A M-7$ (disintegrin and metalloproteinase domain-containing protein 7), c) SLCO1A2 (solute carrier organic anion transporter family member 1A2), d) TMEFF2 (transmembrane protein with epidermal growth factor like and two follistatin like domains 2) and e) TRPM-1 (transient receptor potential cation channel subfamily $\mathrm{M}$ member 1) associated with submucosal eosinophils (adjusted for age and sex) in the bronchial brushing samples.

bronchoscopy study and we had analysable biopsies from 137 (87\%) of these. This success was due to the harmonisation of the SOPs across all centres, training in bronchoscopy and biopsy handling, and ongoing feedback to clinical centres about the quality of collected biopsies. To the best of our knowledge, this represents the largest cohort with such a comprehensive sample collection combined with "omics" measurements.

Several studies have reported a reduction in submucosal mast cells with inhaled and oral steroid therapy [24-26], and BALZAR et al. [27] in the SARP study report reduced numbers of tryptase-positive mast cells in airway biopsies in severe asthma. Thus, the reduction in mast cells we have observed is likely due to the effects of inhaled corticosteroid treatment that all of our asthma subjects were taking. There was a lack of any other asthma-related airway inflammatory signal at this proximal airway site, including significant

\begin{tabular}{|c|c|c|c|}
\hline & \multicolumn{2}{|c|}{ Group } & \multirow[t]{2}{*}{ p-value } \\
\hline & Eosinophil-low $\#$ & Eosinophil-high ๆ & \\
\hline Subjects & 126 & 11 & \\
\hline Blood eosinophils \% & $2.72(1.5-4.28)$ & $4.76(2.36-8.85)$ & 0.025 \\
\hline Sputum eosinophils \% & $0.33(0-2.03)$ & $4.64(1.87-25.43)$ & 0.048 \\
\hline Submucosal eosinophils $\mathrm{mm}^{-2}$ & $2.17(0.59-5.07)$ & $16.48(13.82-23.11)$ & $<0.001$ \\
\hline Submucosal macrophages $\mathrm{mm}^{-2}$ & $2.17(0.95-4.20)$ & $7.94(4.83-11.61)$ & 0.006 \\
\hline Submucosal $\mathrm{CD}^{+}$lymphocytes $\mathrm{mm}^{-2}$ & $33.52(17.92-47.87)$ & $77.17(45.12-96.78)$ & 0.001 \\
\hline Submucosal $\mathrm{CD4}^{+}$lymphocytes $\mathrm{mm}^{-2}$ & $9.57(4.41-17.78)$ & $23.91(10.74-30.45)$ & 0.003 \\
\hline Submucosal CD8 ${ }^{+}$lymphocytes $\mathrm{mm}^{-2}$ & $15.38(7.14-25.56)$ & $37.42(29.25-44.04)$ & $<0.001$ \\
\hline Submucosal CD25+ lymphocytes $\mathrm{mm}^{-2}$ & $0(0-0)$ & $0.79(0-1.04)$ & $<0.001$ \\
\hline
\end{tabular}

Data are presented as $\mathrm{n}$ or median (interquartile range), unless otherwise stated. ${ }^{\#}: \leqslant 12.63 \mathrm{~mm}^{-2}$; १: $>12.63 \mathrm{~mm}^{-2}$. 
airway eosinophilia, which is also reported in the SARP study [15]. This is also likely to be a reflection of the steroid treatment, as type 2 inflammation has been shown to be highly steroid sensitive [16]. In this study this is evidenced by the upregulation of gene expression of a common molecular marker of glucocorticosteroid response, FK506 binding protein 5 (FKBP5) [28], in the bronchial epithelial cell gene array analysis. The FKBP5 epithelial gene signal was significantly increased in all of the three asthma groups compared with the HC group (see online supplementary material). Additionally the Medicines Adherence Response Scale scores recorded for these three asthma groups were in the range of 21-22, with the severe asthma groups recording higher scores, suggesting good adherence with steroid therapy.

We found no difference in the thickness of the lamina reticularis in severe asthma compared with healthy controls. There are some reports of this being a hallmark of asthma that relates to severity [7], but others like us do not observe an increase $[5,6]$. There was, however, a correlation between markers of eosinophilic inflammation and lamina reticularis thickness suggestive of the link between these two processes. This is consistent with a previous report identifying that the lamina reticularis thickness was significantly higher in eosinophilic as compared with noneosinophilic severe asthma and that it was only in eosinophilic severe asthma that there were differences from that in healthy individuals [13].

To the best of our knowledge, there are no previous studies examining the association of smoking with airway inflammation in severe asthma. A reduction in $\mathrm{CD}^{+}$lymphocytes, as observed by us, has been reported when comparing smoking and nonsmoking mild asthma with occupational asthma [29]. We also saw an increase in absolute numbers of neutrophils in the blood and a decrease in FeNO in the SAs/ex group compared with the SAn group. These effects are also reported in milder asthma [30-32]. Other inflammatory changes observed in response to smoking in milder asthma include a reduction in blood [30] and sputum eosinophils [30, 33], increases in sputum neutrophils [29], and increased submucosal CD ${ }^{+}$ lymphocytes and macrophages in bronchial biopsies [34]; however, we did not see these differences in our severe asthma subjects.

When attempting to stratify our data by eosinophilia, the majority of the participants had tissue eosinophil counts within our defined normal range (mean+2SD of healthy controls), consistent with effective glucocorticoid-related anti-inflammatory effects within their proximal airways or having a noninflamed bronchial mucosa. However, the 11 participants who were in the eosinophil-high group had higher percentages of eosinophils in the blood and sputum, greater numbers of submucosal macrophages, $\mathrm{CD}^{+}$, $\mathrm{CD}^{+}, \mathrm{CD}^{+}$and $\mathrm{CD} 25^{+}$T-lymphocytes, and higher numbers of epithelial eosinophils than the eosinophil-low group. This is consistent with a type 2 inflammatory response. This needs to be interpreted cautiously due to the small numbers, but could represent a group that is either refractory to steroid therapy or noncompliant with medication. Two of the participants in this group were healthy controls. One of these individuals was atopic and had seasonal allergic rhinitis, and the other had nasal polyps, i.e. factors that can lead to inflammation within the lower airways [35].

One of the strengths of the U-BIOPRED bronchoscopy study was that it not only assessed proximal tissue events but also assessed inflammatory cell numbers in sputum and blood, as well as FeNO concentrations. In the SAn group there were increases in both sputum eosinophils and neutrophils compared with the HC group, and this SAn group eosinophilia was also greater than in the MMA group. Despite no changes in these cells in the bronchial mucosa there was a positive relationship between the number of eosinophils in the blood, but not sputum, and in the bronchial submucosa, epithelium and ASM across the groups. This could suggest that there is ongoing recruitment and trafficking of eosinophils into the airway lumen. These eosinophil changes were accompanied by elevated FeNO in the SAn group compared with the HC group, but not the MMA group. FeNO is reported to correlate with airway eosinophilia $[36,37]$ and we observed a positive relationship with submucosal eosinophils with FeNO when assessed across all groups.

We identified seven associations in the bronchial brushings that were linked to submucosal eosinophils. These included probes for COX-2, ADAM-7, SLCO1A2, TMEFF2 and TRPM-1, and two unnamed genes. This was obtained by using a very stringent level of false discovery, which was required as this present study did not include an external validation group. The enzyme COX-2 is induced during inflammation and is involved in the synthesis of prostaglandins, converting arachidonic acid to prostaglandin $\mathrm{H}_{2}$ [38]. Its expression, which is localised to the bronchial epithelium and submucosal inflammatory cells, is reported to be increased in expression in mild asthma and aspirin-sensitive asthma compared with healthy controls [39-41]. To the best of our knowledge, there are no reports of its expression levels in severe asthma. The relevance of the other genes is less clear, as there no reports of these in asthma.

From this U-BIOPRED bronchoscopy study of 96 participants with asthma and 41 healthy controls, we conclude that in nonsmoking and smoking patients on currently recommended therapy, severe asthma exists despite suppressed endobronchial tissue inflammation within the proximal airways. This suggests that additional mechanisms in central airways or altered peripheral airway changes are contributing to asthma severity. 


\section{Acknowledgements}

Members of the U-BIOPRED study group are as follows: A. Sogbesan (Royal Brompton and Harefield NHS Foundation Trust, London, UK), A. Knox (Respiratory Research Unit, University of Nottingham, Nottingham, UK), A. Mazein (European Institute for Systems Biology and Medicine, CNRS-ENS-UCBL-INSERM, CIRI-UMR5308, Lyon, France), A. Berton (AstraZeneca, Mölndal, Sweden), A. Roberts (Asthma UK, London, UK), A. Chaiboonchoe (European Institute for Systems Biology and Medicine, CNRS-ENS-UCBL-INSERM, CIRI-UMR5308, Lyon, France), A. Bautmans (MSD, Brussels, Belgium), A.R. Sousa (Respiratory Therapeutic Unit, GSK, Stevenage, UK), A. Meiser (National Heart and Lung Institute, Imperial College, London, UK), A. Menzies-Gow (Royal Brompton and Harefield NHS Foundation Trust, London, UK), A. Berglind (Dept of Women's and Children's Health and Centre for Allergy Research, Karolinska Institutet, Stockholm, Sweden), A.-S. Lantz (Karolinska University Hospital and Centre for Allergy Research, Karolinska Institutet, Stockholm, Sweden), A.J. James (Centre for Allergy Research, Karolinska Institutet, Stockholm, Sweden), A. Petrén (Centre for Allergy Research, Karolinska Institutet, Stockholm, Sweden), A.F. Behndig (Dept of Public Health and Clinical Medicine, Umeå University, Umeå, Sweden), A. Dijkhuis (Academic Medical Centre, University of Amsterdam, Amsterdam, The Netherlands), A. Postle (University of Southampton, Southampton, UK), A. Rowe (Janssen R\&D, High Wycombe, UK), A. Vink (Philips Research Laboratories, Eindhoven, The Netherlands), A. Pacino (Lega Italiano Anti Fumo, Catania, Italy), A. Aliprantis (Merck Research Laboratories, Boston, MA, USA), A. Wagener (Academic Medical Centre, University of Amsterdam, Amsterdam, The Netherlands), A. Braun (Fraunhofer Institute for Toxicology and Experimental Medicine, Hannover, Germany), A. D’Amico (University of Rome "Tor Vergata", Rome, Italy), A.T. Bansal (Acclarogen, St John's Innovation Centre, Cambridge, UK), A. Woodcock (Centre for Respiratory Medicine and Allergy, Institute of Inflammation and Repair, University of Manchester and University Hospital of South Manchester, Manchester Academic Health Sciences Centre, Manchester, UK), B. Smids (Academic Medical Centre, University of Amsterdam, Amsterdam, The Netherlands), B. Dahlén (Karolinska University Hospital and Centre for Allergy Research, Karolinska Institutet, Stockholm, Sweden), B. Lambrecht (University of Gent, Gent, Belgium), B. Nicholas (University of Southampton, Southampton, UK), B. De Meulder (European Institute for Systems Biology and Medicine, CNRS-ENS-UCBL-INSERM, CIRI-UMR5308, Lyon, France), B. Nordlund (Dept of Women's and Children's Health and Centre for Allergy Research, Karolinska Institutet, Stockholm, Sweden), B. Thornton (MSD, Kenilworth, NJ, USA), B. Flood (Asthma UK, London, UK), C. Mathon (Centre of Allergy Research, Karolinska Institutet, Stockholm, Sweden), C. Smith (NIHR Southampton Respiratory Biomedical Research Unit, Southampton, UK), C. Holweg (Respiratory and Allergy Diseases, Genentech, San Francisco, CA, USA), C. Auffray (European Institute for Systems Biology and Medicine, CNRS-ENS-UCBL-INSERM, CIRI-UMR5308, Lyon, France), C. Compton (Respiratory Therapeutic Unit, GSK, Stevenage, UK), C. von Garnier (University Hospital Bern, Bern, Switzerland), C. Rossios (National Heart and Lung Institute, Imperial College, London, UK), C. Barber (NIHR Southampton Respiratory Biomedical Research Unit and Clinical and Experimental Sciences, Southampton, UK), C.S. Murray (Centre for Respiratory Medicine and Allergy, Institute of Inflammation and Repair, University of Manchester and University Hospital of South Manchester, Manchester Academic Health Sciences Centre, Manchester, UK), C. Wiegman (National Heart and Lung Institute, Imperial College, London, UK), C. Schoelch (Boehringer Ingelheim Pharma, Biberach, Germany), C. Faulenbach (Fraunhofer ITEM, Hannover, Germany), C. Coleman (Asthma UK, London, UK), C.E. Wheelock (Centre for Allergy Research, Karolinska Institutet, Stockholm, Sweden), C. Gomez (Centre for Allergy Research, Karolinska Institutet, Stockholm, Sweden), D. Erzen (Boehringer Ingelheim Pharma, Biberach, Germany), D. Balgoma (Centre for Allergy Research, Karolinska Institutet, Stockholm, Sweden), D. Gibeon (National Heart and Lung Institute, Imperial College, London, UK), D. Myles (Respiratory Therapeutic Unit, GSK, Stevenage, UK), D. Supple (Asthma UK, London, UK), D. Campagna (Dept of Clinical and Experimental Medicine, University of Catania, Catania, Italy), D. Lefaudeux (European Institute for Systems Biology and Medicine, CNRS-ENS-UCBL-INSERM, CIRI-UMR5308, Lyon, France), D. Burg (Centre for Proteomic Research, Institute for Life Sciences, University of Southampton, Southampton, UK), D.E. Shaw (Respiratory Research Unit, University of Nottingham, Nottingham, UK), D. Staykova (University of Southampton, Southampton, UK), E. Bel (Academic Medical Centre, University of Amsterdam, Amsterdam, The Netherlands), E. Henriksson (Karolinska University Hospital and Karolinska Institutet, Stockholm, Sweden), E. Yeyasingham (UK Clinical Operations, GSK, Uxbridge, UK), E. Ray (NIHR Southampton Respiratory Biomedical Research Unit, Southampton, UK), E.J. Kennington (Asthma UK, London, UK), F. Singer (University Children's Hospital, Zurich, Switzerland), F. Wald (Boehringer Ingelheim Pharma, Biberach, Germany), F. Baribaud (Janssen R\&D, Spring House, PA USA), G. Galffy (Semmelweis University, Budapest, Hungary), G. Pennazza (University of Rome "Tor Vergata", Rome, Italy), G. Santini (Università Cattolica del Sacro Cuore, Milan, Italy), G. Roberts (NIHR Southampton Respiratory Biomedical Research Unit, Clinical and Experimental Sciences and Human Development and Health, Southampton, UK), G. Bochenek (II Dept of Internal Medicine, Jagiellonian University Medical College, Krakow, Poland), G. Hedlin (Dept of Women's and Children's Health and Centre for Allergy Research, Karolinska Institutet, Stockholm, Sweden), H. Bisgaard (COPSAC, Copenhagen Prospective Studies on Asthma in Childhood, Herlev and Gentofte Hospital, University of Copenhagen, Copenhagen, Denmark), H. Ahmed (European Institute for Systems Biology and Medicine, CNRS-ENS-UCBL-INSERM, CIRI-UMR5308, Lyon, France), H. Gallart (Centre for Allergy Research, Karolinska Institutet, Stockholm, Sweden), H. Knobel (Philips Research Laboratories, Eindhoven, The Netherlands), I. Adcock (National Heart and Lung Institute, Imperial College, London, UK), I. Horvath (Semmelweis University, Budapest, Hungary), I. De Lepeleire (MSD, Brussels, Belgium), I. Delin (Centre for Allergy Research, Karolinska Institutet, Stockholm, Sweden), I. Pandis (Data Science Institute, Imperial College, London, UK), J. Musial (II Dept of Internal Medicine, Jagiellonian University Medical College, Krakow, Poland), J.P.R. Schofield (Centre for Proteomic Research, Institute for Life Sciences, University of Southampton, Southampton, UK), J. Martin (NIHR Southampton Respiratory Biomedical Research Unit, Southampton, UK), J. Bigler (Amgen, Thousand Oaks, CA, USA), J. Versnel (Asthma UK, London, UK), J. Hohlfeld (Fraunhofer Institute for Toxicology and Experimental Medicine, Hannover, Germany), J. Edwards (Asthma UK, London, UK), J. Smith (Asthma UK, London, UK), J.P. Carvalho da Purificação Rocha (Royal Brompton and Harefield NHS Foundation Trust, London, UK), J. Kolmert (Centre for Allergy Research, Karolinska Institutet, Stockholm, Sweden), J.G. Matthews (Respiratory and Allergy Diseases, Genentech, San Francisco, CA, USA), J. Haughney (International Primary Care Respiratory Group, Aberdeen, UK), J. Riley (Respiratory Therapeutic Unit, GSK, Stevenage, UK), J.-O. Thörngren (Karolinska University Hospital, Sweden), J. Konradsen (Dept of Women's and Children's Health and Centre for Allergy Research, Karolinska Institutet, Stockholm, Sweden), J. Thorsen (COPSAC, Copenhagen Prospective Studies on Asthma in Childhood, Herlev and Gentofte Hospital, University of Copenhagen, Copenhagen, Denmark), J. Ward (Histochemistry Research Unit, Faculty of Medicine, 
University of Southampton, Southampton, UK), J. Brandsma (University of Southampton, Southampton, UK), J. Beleta (Almirall, Barcelona, Spain), J. De Alba (Almirall, Barcelona, Spain), J. Östling (AstraZeneca, Mölndal, Sweden), J. Vestbo (Centre for Respiratory Medicine and Allergy, Institute of Inflammation and Repair, University of Manchester and University Hospital of South Manchester, Manchester Academic Health Sciences Centre, Manchester, UK), J. Gent (Royal Brompton and Harefield NHS Foundation Trust, UK), J. Corfield (Areteva R\&D, Nottingham, UK), J. Kamphuis (Longfonds, Amersfoort, The Netherlands), K. Sun (National Heart and Lung Institute, Imperial College, London, UK), K. Tariq (NIHR Southampton Respiratory Biomedical Research Unit, Clinical and Experimental Sciences, NIHR-Wellcome Trust Clinical Research Facility, Faculty of Medicine, University of Southampton, Southampton, UK), K. Strandberg (Karolinska University Hospital and Karolinska Institutet, Stockholm, Sweden), K.M. Smith (University of Nottingham, Nottingham, UK), K. Riemann (Boehringer Ingelheim Pharma, Biberach, Germany), K. Nething (Boehringer Ingelheim Pharma, Biberach, Germany), K. van Drunen (Academic Medical Centre, University of Amsterdam, Amsterdam, The Netherlands), K. Dyson (CromSource, Stirling UK), K. Gove (NIHR Southampton Respiratory Biomedical Research Unit and Clinical and Experimental Sciences, Southampton, UK), K.F. Chung (National Heart and Lung Institute, Imperial College, London, UK), K. Russell (National Heart and Lung Institute, Imperial College, London, UK), K. Alving (Dept of Women's and Children's Health, Uppsala University, Sweden), K. Bøonnelykke (COPSAC, Copenhagen Prospective Studies on Asthma in Childhood, Herlev and Gentofte Hospital, University of Copenhagen, Copenhagen, Denmark), K. Fichtner (Boehringer Ingelheim Pharma, Biberach, Germany), K. Zwinderman (Academic Medical Centre, University of Amsterdam, Amsterdam, The Netherlands), K. Wetzel (Boehringer Ingelheim Pharma, Biberach, Germany), L. Ravanetti (Academic Medical Centre, University of Amsterdam, Amsterdam, The Netherlands), L. Larsson (AstraZeneca, Mohlndal, Sweden), L. Pahus (Assistance publique des Hôpitaux de Marseille, Clinique des bronches, allergies et sommeil Espace Éthique Méditerranéen, Aix-Marseille Université, Marseille, France), L. Metcalf (Asthma UK, London, UK), L. Carayannopoulos (MSD, Kenilworth, NJ, USA), L. Tamasi (Semmelweis University, Budapest, Hungary), L. Krueger (University Children's Hospital Bern, Bern, Switzerland), L. Marouzet (NIHR Southampton Respiratory Biomedical Research Unit, Southampton, UK), L. Hewitt (NIHR Southampton Respiratory Biomedical Research Unit, Southampton, UK), L.J. Fleming (National Heart and Lung Institute, Imperial College, London, UK), M. Kupczyk (Centre for Allergy Research, Karolinska Institutet, Stockholm, Sweden), M. Ericsson (Karolinska University Hospital, Stockholm, Sweden), M. Rahman-Amin (Asthma UK, London, UK), M. Santoninco (University of Rome "Tor Vergata", Rome, Italy), M. Sjödin (Centre for Allergy Research, Karolinska Institutet, Stockholm, Sweden), M. Gerhardsson de Verdier (AstraZeneca, Mölndal, Sweden), M. Mikus (Science for Life Laboratory and The Royal Institute of Technology, Stockholm, Sweden), M. van de Pol (Academic Medical Centre, University of Amsterdam, Amsterdam, The Netherlands), M. van Geest (AstraZeneca, Mölndal, Sweden), M. Gahlemann (Boehringer Ingelheim (Schweiz), Basel, Switzerland), M. Robberechts (MSD, Brussels, Belgium), M. Szentkereszty (Semmelweis University, Budapest, Hungary), M. Caruso (Dept of Clinical and Experimental Medicine, University of Catania, Catania, Italy), M.J. Loza (Janssen R\&D, Spring House, PA, USA), M. Klüglich (Boehringer Ingelheim Pharma, Biberach, Germany), M. Kots (Chiesi Pharmaceuticals, Parma, Italy), M. Rutgers (Longfonds, Amersfoort, The Netherlands), M.J. Boedigheimer (Amgen, Thousand Oaks, CA, USA), M. Miralpeix (Almirall, Barcelona, Spain), N. Mores (Università Cattolica del Sacro Cuore, Milan, Italy), N. Vissing (COPSAC, Copenhagen Prospective Studies on Asthma in Childhood, Herlev and Gentofte Hospital, University of Copenhagen, Copenhagen, Denmark), N. Rao (Janssen R\&D, San Diego, CA, USA), N. Fitch (BioSci Consulting, Maasmechelen, Belgium), N. Gozzard (UCB, Slough, UK), N. Lazarinis (Karolinska University Hospital and Karolinska Institutet, Stockholm, Sweden), N. Adriaens (Academic Medical Centre, University of Amsterdam, Amsterdam, The Netherlands), N. Krug (Fraunhofer Institute for Toxicology and Experimental Medicine, Hannover, Germany), P.J. Carvalho (National Heart and Lung Institute, Imperial College, London, UK), P. Söderman (Dept of Women's and Children's Health, Karolinska Institutet, Stockholm, Sweden), P. Montuschi (Università Cattolica del Sacro Cuore, Milan, Italy), P. Chanez (Assistance publique des Hôpitaux de Marseille, Clinique des bronches, allergies et sommeil, Aix-Marseille Université, Marseille, France), P. Dennison (NIHR Southampton Respiratory Biomedical Research Unit, Clinical and Experimental Sciences, NIHR-Wellcome Trust Clinical Research Facility, Faculty of Medicine, University of Southampton, Southampton, UK), P. Brinkman (Academic Medical Centre, University of Amsterdam, Amsterdam, The Netherlands), P.J. Skipp (Centre for Proteomic Research, Institute for Life Sciences, University of Southampton, Southampton, UK), P. Bakke (Dept of Clinical Science, University of Bergen, Bergen, Norway), P. Howarth (NIHR Southampton Respiratory Biomedical Research Unit, Clinical and Experimental Sciences, Southampton, UK), P.J. Sterk (Academic Medical Centre, University of Amsterdam, Amsterdam, The Netherlands), P. Nilsson (Science for Life Laboratory and The Royal Institute of Technology, Stockholm, Sweden), P. Monk (Synairgen Research, Southampton, UK), P. Badorrek (Fraunhofer ITEM, Hannover, Germany), P.-P. Hekking (Academic Medical Centre, University of Amsterdam, Amsterdam, The Netherlands), P. de Boer (Longfonds, Amersfoort, The Netherlands), P. Powell (European Lung Foundation, Sheffield, UK), R. Sigmund (Boehringer Ingelheim Pharma, Biberach, Germany), R. Djukanovic (NIHR Southampton Respiratory Biomedical Research Unit and Clinical and Experimental Sciences, Southampton, UK), R. Lutter (Academic Medical Centre, University of Amsterdam, Amsterdam, The Netherlands), R. Hu (Amgen, Thousand Oaks, CA, USA), R. Knowles (Arachos Pharma, Stevenage, UK), R. Middelveld (Centre for Allergy Research, Karolinska Institutet, Stockholm, Sweden), R. Chaleckis (Centre of Allergy Research, Karolinska Institutet, Stockholm, Sweden), R. Emma (Dept of Clinical and Experimental Medicine, University of Catania, Catania, Italy), S. Lone-Latif (Academic Medical Centre, University of Amsterdam, Amsterdam, The Netherlands), S. Meah (National Heart and Lung Institute, Imperial College, London, UK), S. Valente (Università Cattolica del Sacro Cuore, Milan, Italy), S. Walker (Asthma UK, London, UK), S. Pink (NIHR Southampton Respiratory Biomedical Research Unit, Southampton, UK), S. Masefield (European Lung Foundation, Sheffield, UK), S. Kuo (National Heart and Lung Institute, Imperial College, London, UK), S. Wagers (BioSci Consulting, Maasmechelen, Belgium), S. Naz (Centre for Allergy Research, Karolinska Institutet, Stockholm, Sweden), S. Williams (International Primary Care Respiratory Group, Aberdeen, UK), S. Hu (National Heart and Lung Institute, Imperial College, London, UK), S. Hashimoto (Academic Medical Centre, University of Amsterdam, Amsterdam, The Netherlands), S. Reinke (Centre for Allergy Research, Karolinska Institutet, Stockholm, Sweden), S. Pavlidis (National Heart and Lung Institute, Imperial College, London, UK), S.J. Fowler (Centre for Respiratory Medicine and Allergy, Institute of Inflammation and Repair, University of Manchester and University Hospital of South Manchester, Manchester Academic Health Sciences Centre, Manchester, UK), S.J. Wilson (Histochemistry Research Unit, Faculty of Medicine, University of Southampton, Southampton, UK), S. Palkonen (European Federation of Allergy and Airways Diseases Patient's Associations, Brussels, Belgium), S.-E. Dahlén (Centre 
for Allergy Research, Karolinska Institutet, Stockholm, Sweden), T. Dekker (Academic Medical Centre, University of Amsterdam, Amsterdam, The Netherlands), T. Geiser (Dept of Respiratory Medicine, University Hospital Bern, Switzerland), T. Sandström (Dept of Public Health and Clinical Medicine, Umeå University, Umeå, Sweden), T. Higgenbottam (Allergy Therapeutics, Worthing, UK), U. Nihlen (AstraZeneca, Mölndal, Sweden), U. Frey (University Children's Hospital, Basel, Switzerland), U. Hoda (Imperial College, London, UK), V. Hudson (Asthma UK, London, UK), V. Erpenbeck (Translational Medicine, Respiratory Profiling, Novartis Institutes for Biomedical Research, Basel, Switzerland), W. Yu (Amgen, Thousand Oaks, CA, USA), W. Zetterquist (Dept of Women's and Children's Health and Centre for Allergy Research, Karolinska Institutet, Stockholm, Sweden), W. van Aalderen (Academic Medical Centre, University of Amsterdam, Amsterdam, The Netherlands), W. Seibold (Boehringer Ingelheim Pharma, Biberach, Germany), X. Yang (National Heart and Lung Institute, Imperial College, London, UK), X. Hu (Amgen, Thousand Oaks, CA, USA), Y.-k. Guo (Data Science Institute, Imperial College, London, UK), Z. Weiszhart (Semmelweis University, Budapest, Hungary).

All the bronchoscopy centres acknowledge the help received from nursing and other healthcare workers in the conduct of this study, and the Histochemistry Research Unit at the University of Southampton acknowledges the help from Helen Rigden and Jana Collier (University of Southampton, Southampton, UK) in assisting with the immunohistochemical analysis of the tissue biopsies. We also recognise that without the voluntary help from the asthmatic participants and the healthy control volunteers this study would not have been possible, and are indebted to their generosity.

\section{References}

Bittar HET, Yousem SA, Wenzel SE. Pathobiology of severe asthma. Annu Rev Pathol Mech 2015; 10: 511-545.

2 European Network for Understanding Mechanisms of Severe Asthma. The ENFUMOSA cross-sectional European multicentre study of the clinical phenotype of chronic severe asthma. Eur Respir J 2003; 22: 470-477.

3 Wenzel SE, Szefler SJ, Leung DYM, et al. Bronchoscopic evaluation of severe asthma; persistent inflammation associated with high does glucocorticoids. Am J Respir Crit Care Med 1997; 156: 737-743.

4 Maccedo P, Hew M, Torrego A, et al. Inflammatory biomarkers in airways of patients with severe asthma compared with non-severe asthma. Clin Exp Allergy 2009; 39: 1668-1676.

5 Benayoun L, Druilhe A, Dombret M-C, et al. Airway structural alterations associated with severe asthma. Am J Respir Crit Care Med 2003; 167: 1360-1368.

6 Pepe C, Foley S, Shannon J, et al. Differences in airway remodelling in subjects with severe and moderate asthma. J Allergy Clin Immunol 2005; 116: 544-549.

7 Bourdin A, Neveu D, Vachier I, et al. Specificity of basement thickening in severe asthma. J Allergy Clin Immunol 2007; 119: 1367-1374.

8 Miranda C, Busacker A, Balzar S, et al. Distinguishing severe asthma phenotypes: role of age at onset and eosinophil inflammation. J Allergy Clin Immunol 2004; 113: 101-108.

9 de Carvalho-Pinto RM, Cukier A, Angelini L, et al. Clinical characteristics and possible phenotypes of an adult severe asthma population. Respir Med 2012; 106: 47-56.

$10 \mathrm{Wu} \mathrm{W}$, Bleecker E, Moore W, et al. Unsupervised phenotyping of severe asthma research program participants using expanded lung data. J Allergy Clin Immunol 2014; 133: 1280-1283.

11 Moore WC, Meyers DA, Li H, et al. Identification of asthma phenotypes using cluster analysis in the severe asthma research program. Am J Respir Crit Care Med 2009; 179: A2522.

12 Halder P, Pavord ID, Shaw DE, et al. Cluster analysis and clinical asthma phenotypes. Am J Respir Crit Care Med 2008; 178: 218-224.

13 Wenzel SE, Schwartz LB, Langmack EL, et al. Evidence that severe asthma can be divided pathologically into two inflammatory subtypes with distinct physiological and clinical characteristics. Am J Respir Crit Care Med 1999; 160: 10001-11008.

14 Simpson JL, Scott R, Boyle MJ, et al. Inflammatory subtypes in asthma: assessment and identification using induced sputum. Respirology 2006; 11: 54-61.

15 Hastie AT, Moore WC, Meyers DA, et al. Analyses of asthma severity phenotypes and inflammatory proteins in subjects stratified by sputum granulocytes. J Allergy Clin Immunol 2010; 125: 1028-1036.

16 Woodruff PG, Modrek B, Choy DF, et al. T-helper type 2-driven inflammation defines major subphenotypes of asthma. Am J Respir Crit Care Med 2009; 180: 388-395.

17 Berry M, Morgan A, Shaw DE, et al. Pathological features and inhaled corticosteroid response of eosinophilic and non-eosinophilic asthma. Thorax 2007; 62: 1043-1049.

18 Kupczyk M, Wenzel S. US and European severe asthma cohorts: what can they teach us about severe asthma? J Int Med 2012; 272: 121-132.

19 Shaw DE, Sousa AR, Fowler SJ, et al. Clinical and inflammatory characteristics of the European U-BIOPRED adult severe asthma cohort. Eur Respir J 2015; 46: 1308-1321.

20 Britten KM, Howarth PH, Roche WR. Immunohistochemistry on resin sections: a comparison of resin embedding techniques for small mucosal biopsies. Biotech Histochem 1993; 68: 271-280.

21 Jarjour NN, Wilson SJ, Koenig SM, et al. Control of airway inflammation maintained at a lower steroid dose with 100/50 microg of fluticasone propionate/salmeterol. J Allergy Clin Immunol 2006; 118: 44-52.

22 Howard CV, Reed MG. Unbiased Stereology. 2nd Edn. New York, BIOS, 2005.

23 Cohen J. Statistical Power Analysis for the Behavioural Sciences. 2nd Edn. Hillsdale, Lawrence Erlbaum, 1988.

24 Wallin A, Sue-Chu M, Bjermer L, et al. Effect of inhaled fluticasone with and without salmeterol on airway inflammation in asthma. J Allergy Clin Immunol 2003; 112: 72-78.

25 Bentley AM, Hamid Q, Robinson DS, et al. Prednisolone treatment in asthma. Reduction in the numbers of eosinophils, T cells, tryptase-only positive mast cells, and modulation of IL-4, IL-5, and interferon-gamma cytokine gene expression within the bronchial mucosa. Am J Respir Crit Care Med 1996; 153: 551-556.

26 Djukanović R, Homeyard S, Gratziou C, et al. The effect of treatment with oral corticosteroids on asthma symptoms and airway inflammation. Am J Respir Crit Care Med 1997; 155: 826-832.

27 Balzar S, Fajt ML, Comhair SAA, et al. Mast cell phenotype, location and activation in severe asthma. Am J Respire Crit Care Med 2011; 183: 299-309. 
Kelly MM, King EM, Rider CF, et al. Corticosteroid-induced gene expression in allergen-challenged asthmatic subjects taking inhaled budesonide. Br J Pharmacol 2012; 165: 1737-1747.

29 Sjåheim T, Kongerud J, Bjørtuft O, et al. Reduced bronchial CD4+ T-cell density in smokers with occupational asthma. Eur Respir J 2006; 28: 1138-1144.

30 Telenga ED, Kerstjens HAM, ten Hacken NHT, et al. Inflammation, and corticosteroid responsiveness in ex-, current- and never-smoking asthmatics. BMC Pulm Med 2013; 13: 58-67.

31 Verleden GM, Dupont LJ, Verpeut AC, et al. The effect of cigarette smoking on exhaled NO in mild steroid naive asthma. Chest 1999; 116: 59-64.

32 McSharry CP, Mckay IC, Chaudhuri R, et al. Short and long-term effects of cigarette smoking independently influence exhaled nitric oxide concentration in asthma. J Allergy Clin Immunol 2005; 116: 88-93.

33 Chalmers G, Macleod K, Thomason L, et al. Smoking and airway inflammation in patients with mild asthma. Chest 2001; 120: 1917-1922.

34 Ravaensberg AJ, Slats AM, van Wetering S, et al. $\mathrm{CD}^{+} \mathrm{T}$ cells characterize early smoking- related airway pathology in patients with asthma. Respir Med 2013; 107: 959-966.

35 Brown JL, Behndig AF, Sekerel BE, et al. Lower airways inflammation in allergic rhinitis: a comparison with asthmatics and normal controls. Clin Exp Allergy 2007; 37: 688-695.

36 Brightling CE, Symon FA, Birrig SS, et al. Comparison of airway immunopathology of eosinophilic bronchitis and asthma. Thorax 2003; 58: 528-532.

37 Van den Toorn LM, Prins JB, Overbeck SE, et al. Adolescents in clinical remission of atopic asthma have elevated exhaled nitric oxide levels and bronchial hyperresponsiveness. Am J Respir Crit Care Med 2000; 162: $953-957$.

38 Claar D, Hartert TV, Peebles RS. The role of prostaglandins in allergic inflammation and asthma. Expert Rev Respir Med 2016; 9: 55-72.

39 Taha R, Olivenstein R, Utsumi T, et al. Prostaglandin H synthase 2 expression in airway cells from patients with asthma and chronic obstructive pulmonary disease. Am J Respir Crit Care Med 2000; 161: 636-640.

40 Demoly P, Jaffuel D, Lequeux N, et al. Prostaglandin H synthase 1 and 2 immunoreactivities in the bronchial mucosa of asthmatics. Am J Respir Crit Care Med 1997; 155: 670-675.

41 Sousa AR, Pfister R, Christie PE, et al. Enhanced expression of cyclo-oxygenase isoenzyme 2 (COX-2) in asthmatic airways and its cellular distribution in aspirin-sensitive asthma. Thorax 1997; 52: 940-945. 